\title{
Pragmatics in ESL Classroom: Its Importance in Listening Skills
}

Leticia PRESOTTO

\begin{abstract}
This article aims at discussing the importance of Pragmatics in ESL classroom, more specifically in listening tasks. In order to base our study, we present an overview of some pragmatic theories which relies on the notion of inference, like Grice (1975) and Sperber and Wilson (1995). Then, we discuss about the importance of Pragmatics among language teaching and listening skill. In this section, we highlight some important aspects that have to be considered in teaching a second language focusing in listening activities. Finally, we analyze the listening section of TOEFL exam. Here, we show how Pragmatics is present and its importance to the students who take this specific test.
\end{abstract}

Keywords: Pragmatics, ESL classroom, Listening tasks.

\section{Introduction}

This paper is going to discuss the importance of Pragmatics in ESL classesand its relation to listening activities. The objective of this work is to demonstrate how Pragmatics can help students understand a second language, more specifically in listening skill. The main aspect which is going to be observed in this process is the notion of inference and its influence in listening tasks.

This way, we are going to review some pragmatic theories that are based on the notion of inference in communication. This review initiates presenting the first model of communication; then we introduce Grice (1975) and his Implicature Theory, in which he developed the notion of inference. Finally, we are going to discuss some aspects of the Relevance Theory (SPERBER AND WILSON, 1995) and how inference and relevance work together.

Furthermore, we are going to take a look at some aspects about Pragmatics, language teaching and listening skill. Basically, we rely on some ideas of Schmidt (1993) about the importance of Pragmatics in ESL classes. We also discuss an example in which Pragmatics influences students' comprehension.Besides, we are going to discuss some aspects of listening skill and the students' difficulties in listening tasks. We chose listening skill because listening is very important in communication. If the hearer does not understand what the speaker tells, the communication will be problematic. This fact shows why teachers have to be aware of Pragmatics importance in ESL classroom.

Then, the next step is to analyzethe listening sectionof TOEFL exam. In this part, we focused on listening activities and what students have to do to be successful in this kind of task. We also check if, in this case, Pragmatics helps or not students to understand better what is being conveyed in the exercise. 


\section{Pragmatics and Communication}

The first model of communication was presented by Shannon and Weaver in 1949. They tried to explain the human communication process through the explanation of a basic concept which involves sending and receiving messages. These authors worked with the concepts of encoding and decoding information. This theory takes language as a code and it also takes communication as the transmission of a message built from that code.

In order to improve some problems of this model, Grice (1975) introduced the idea of implicature. Grice was intended to develop a set of theoretical notions to justify an inferential model of communication. He suggested that conversation is based on a shared principle of cooperation, in other words, he suggested that the inferences are derived deductively from the existence of a tacit agreement of cooperation between speaker and hearer:

Make your conversational contribution what is required, at the stage at which it occurs, by the accepted purpose or direction of the talk exchange in which you are engaged. (GRICE, 1975)

The principle of cooperation was composed by four maxims: quantity, quality, relation (relevance), and manner. Grice tried to demonstrate that speaker and listener had to follow these maxims in order to have a successful communication. The violation of these maxims forms the basis for inferences that we draw in conversation, which Grice called. He asserted that different ways of violating these maxims give rise to different types of implicatures.

From Grice's studies, Sperber and Wilson $(1986,1995)$ develop a theory of communication focused on the understanding of utterances. According to Sperber e Wilson's theoretical model, the Relevance Theory (RT), communication isan inferential process, in which the speaker produces stimuli - utterances - from which the audience infers the ideas the speaker intends to state. The relevance of the information, whose central point is inference, is built in a cognitive environment mutually shared between the speaker and the listener.

In this way, Sperber and Wilson based their theoretical model on the idea that we commonly pay attention to stimuli that, to some extent, come to meet our interests or fit the circumstances of the moment. For Sperber and Wilson, the mutual manifestation in RT is achieved through an ostensible-inferential behavior between speakers and listeners. Initially, the speaker means to make explicitly manifest to the listener that he or she wants to communicate something, in other words, they want to draw the listener's attention so that they will be willing to interpret what is said.

According to Sperber and Wilson, meaning is conveyed by the combination of text and context. RT works with cognition to address human communication, not fixating only in the 
linguistic aspect. The authors base their theory in the following principle: Every act of ostensible communication imparts the expectation of maximum relevance.

Still in this aspect, there is the search for the best ratio between processing cost and contextual effects, namely a cost-benefit ratio, which is the Principle of Relevance. The cost is the mental effort necessary to comprehend what the speaker is attempting to communicate. The benefit is the contextual effect obtained through this effort. Thus, the smaller the cost required, and the greater the benefit achieved, the more relevant will the intended interpretation be.

According to the RT, the suppositions the speaker wishes to communicate can be analyzed in under two different views: explicatures and implicatures. Explicatures are suppositions which may be implied by a text or statement, in other words, they are the inference the author wishes to communicate. They are combinations of linguistically coded features and conceptual features inferred through context. Implicatures, however, relate to contextual suppositions and inferences of a text or statement that is necessary to establish relevance. Both explicatures and implicatures are identified by the listener, based on the Principle of Relevance.

These theoretical models about communication were being developed through the passing years. Relying on these latest theories, we can see that the term 'inference' is basic for them. In order to make it clear, we are going to link it to listening skills and ESL classroom. Listening is part of the social interaction and it is very important to the communicative system. The listener is an important character of communication because he has to understand what is being conveyed. He is responsible for understanding and comprehending the message and its inferences. For this purpose, we are going to analyze the listening section of TOEFL exam.

\section{Pragmatics, Language Teaching and Listening Skill}

Why is Pragmatic so important in language classes? How can it help a student understand better the target language? These are some guiding questions in our study, and they will lead us to our main objective: understand if Pragmatics can help studentsin learning a second language, more specifically in listening activities.

According to Schmidt (1993), pragmatic and discursive knowledge is not always used automatically, without thinking; some conversational acts, for example, are planned, others are not; and there is no spontaneity planning. On many occasions, we plan before making a phone call, for example; or we think about the appropriate language in a specific situation, ifthe language is suitable or not, etc.

Hence, the author mentioned above proposes two fundamental approaches to teaching conversation in second language: the first is the indirect approach, in which the conversational competence is seen as a product of student involvement in conversational interaction. In this perspective, the ability to talk is simply something acquired during the interaction process. The 
second is the direct approach, which explicitly focuses on the strategies involved in the conversation and emphasizes awareness on such strategies.

Furthermore, for Schmidt, the pragmatic knowledge is partly explicit and partly implicit. This aspect can be linked to exploring inferences in second language classes. For example, imagine the following scene:

Peter has a very difficult test tomorrow morning. He is studying hard and he asks Mary:

Peter: "What time is it?"

Mary: "It's late."

From this small dialogue, we can have some possible inferences. According to RT, we can infer that Mary wanted to inform Peter that he has to go to bed because his test was going to be in the following morning. Usually, when we have a test in the morning, we try to have a good night of sleep, in order to rest and feel good when we wake up. Another possible inference is that Mary wanted to suggest that there was no time left for Peter to study, because it was late and he had to go to sleep. We can also understand that she is suggesting that it is useless for him to study more that time and that he should have studied more before.

Another simple example can be the following situation: there is a classroom with 30 students, the windows are all closed. The professor comes in and says: "Oh, it's so hot in here!" If the students think pragmatically, they will infer that the professor was asking them to open the windows in order to make the classroom cooler.

From these examples, we suggest that if the students are not aware of those possible inferences, some of them,perhaps, will not understand whatthe real intention of communication was.This way, the idea ofexplicating pragmatic knowledge on teaching a language is important in order to bring to consciousness the pragmatic aspects, the attention to form and function and the relevant contextual features and the possible different contexts involved in communicative act.

Therefore, pragmatic awareness in ESL classroom is important, and language teachers should worry about the attention to linguistic forms, the functional meanings, the relevant contexts, as key elements in this process. A necessary condition for learning is the perception of the input, not from any input, but that one that has an important role in the system being learned. It seems that pragmatic awareness begins with the recognition itself from the student that there is a level beyond the lexical-grammar, which is linked to the perception of socio-cultural differences.

Besides that, "without the explicit teaching of pragmatics, language learners' pragmatic competence will vary a lot regardless of their language background or language proficiency" (CORSETTI, 2010).

\section{Listening Task - Analysis of TOEFL}


From the TOEFL test -one of the most widely known English-language test in the world, recognized by more than 9,000 colleges, universities and agencies in more than 130 countries -, we are going to analyze if the listening section proposed in the exam explores the pragmatic notion of the student.

Some of the most difficult questions in the TOEFL listening section are concerned with the pragmatic function of the speaker, which is the meaning a speaker wishes to convey to the person they are speaking to. Usually, the meaning of the individual words will give the addressee the meaning that the speaker wants to give, but not always. What has to be considered is what is being said, who is saying it, to whom is it being said, and the context in which it is being said, for example.

The listening section of TOEFL is composed by three different types of discourses: conversations, academic discussions and lectures. Some of them use formal language while others are more casual. Normally, conversations take place between two students, or friends, or a student and a university employee, and the topics are commonly about life on campus. Academic discussions occur in the classroom scenario and they demonstrate how professors and students communicate in class. Usually, the professor does most of the talking. Finally, there are the lectures, which involve only one speaker. In this part, the objective of the exercise is to test the ability to comprehend academic subject material spoken by a professor. The topics worked in this part are subjects from Art, Geology, Biology, etc.

After listening to each section, the student has to answer some questions, which generally are presented in the same order as the information conveyed. The student will find different kinds of questions in TOEFL test. The first type are the general questions, like "What is the main topic of the lecture?", "Why does the professor ask (...)?", "What is the discussion mainly about?". This kind of questions tests the student's ability to understand the main idea of what he had heard, for example. They are not about specific details.In this case, it is necessary to pay attention to the whole conversation and try to understand what the speakers are talking about.

The second type of questions is the ones based on details: "According to the professor, what is the problem with (...)?", "What does the student say about (...)?" For this kind of questions, the student can take some notes while listening to the discourse in order to help him answer them. Thereby, the student has to understand the whole conversation and also pay attention to important details.

Another type of questions is related to understanding the attitudes of the speaker, the context of the speech and the possible connections present in the discourse. In this case, we can see that some terms from Pragmatics are used, like 'infer' and 'imply'. Some examples of this type are: "What does the student imply when she says this (...)?", "How does the professor feel about (...)?", "What does the student imply when he says (...)?", "Why does the speaker 
mention (...)?".This kind of question explores the ability of the student in a pragmatic way. Beyond understanding the whole thing and the details, the student has to interpret some ideas. Besides, the student has to explain what the intention of the speaker was when he/she uses a specific expression, or even explain why the speaker says something in a particular way.

From all these arguments, we can perceive that these questions explore Pragmatics in its process. The student who is taking TOEFL test has to know vocabulary, grammar and also identify different contexts, manners and attitudes. In this way, we can see that inferences are intrinsic in this process; therefore, making the student pragmatically aware in future real situations.

\section{Final Remarks}

The present paper presented a discussion focusing on the influence of Pragmatics in ESL classroom, more specifically in listening tasks. Our objective was to promote awareness about how important Pragmatics is when learning a second language, in this case, English.

In order to achieve our objective, we made a link between pragmatic theories, focusing on inferences, and language teaching and listening activities. We also analyzed the listening section of TOEFL test. After all these work, we came to a conclusion: Pragmatics helps students to learn a second language and it should be present in language teaching classes. The analysis of listening tasks showed us how important the practice of understanding what is being conveyed is. In real life, in a real communication, people need to pay attention to the speaker talking in order to understand what he is really saying and meaning. If students are aware of the function of Pragmatics, the will be more competent in their second language. We can refer to Schmidt (2010) to rely this fact: "In order to acquire pragmatics, one must attend to both the linguistic form of utterances and the relevant social and contextual features with which they are associated". From this argument, it is possible to check that the pragmatic aspects in TOEFL listening section help students to improve pragmatic competence.

Therefore, teachers need to apply pragmatic aspects in ESL classes and make their students aware of the possible inferences an utterance can convey. Thus, this paper provided an insight on the inferential abilities and pragmatic knowledge to be developed in ESL classes, in order to make the learners an efficient speaker of English. 


\section{References}

CORSETTI, C. Pragmatic competence in the listening paper of the Certificate of Proficiency in English. Porto Alegre, 2010. Available in:

http://revistaseletronicas.pucrs.br/fo/ojs/index.php/belt/article/view/7266/5232

GRICE, P. Logic and Conversation. In COLE, P.; MORGAN, J. (eds.) Syntax and Semantics. New York: Academic Press, v.3, 1975.

SCHMIDT, R. Attention, awareness, and individual differences in language learning. In

W. M. Chan, S. Chi, K. N. Cin, J. Istanto, M. Nagami, J.W. Sew, T. Suthiwan, \& I. Walker, Proceedings of CLaSIC 2010. Singapore: National University of Singapore,Centre for Language Studies, 2010.

SCHMIDT, R..Consciousness, Learning, and Interlanguage Pragmatics. In: Kasper, G.; Blum-Kulka, S. (ed.) Interlanguge Pragmatics. Oxford University Press, 1993.

SPERBER, D.; WILSON D. Relevance: Communication and cognition. 2 ed. Cambridge: Basil Blackwell, 1995. 